\title{
Research on Friction Material with Carbon Fiber and Melamine Modified Phenolic Resin
}

\author{
School of Mechanical Engineering, University of Jinan, Jinan, China \\ Email address: \\ wangchengminxyz@163.com (Wang Chengmin), me_yangxf@ujn.edu.cn (Yang Xuefeng) \\ ${ }^{*}$ Corresponding author
}

Wang Chengmin, Yang Xuefeng*, Cai Xiguang, Li Yunxi, Guan Yonghao, Zhang Hui

To cite this article:

Wang Chengmin, Yang Xuefeng, Cai Xiguang, Li Yunxi, Guan Yonghao, Zhang Hui. Research on Friction Material with Carbon Fiber and Melamine Modified Phenolic Resin. American Journal of Mechanics and Applications. Vol. 4, No. 1, 2016, pp. $20-24$.

doi: 10.11648/j.ajma.20160401.14

Received: November 9, 2016; Accepted: November 28, 2016; Published: December 1, 2016

\begin{abstract}
A friction material was developed after studying carbon fiber and melamine modified phenolic resin, which was made by thermo-compression craft. Thermal stress coupled field of friction material is analyzed by ABAQUS finite element software, the physical mechanical and friction and wear performance were investigated, the worn surfaces wear mechanism of friction materials were observed by Scanning Electron Microscope (SEM)and x-ray diffractometer, and comparison with ordinary phenolic resin friction material. It is shown that the friction and wear performance can be improved for friction material using both carbon fiber and melamine modified phenolic resin at the condition of high temperature, and the thermal decomposition and thermal fading of friction material were reduced in braking process. The mechanical properties and friction and wear properties of friction materials of melamine modified resin are improved compared with the friction materials of phenolic resin brake pads. It is thermal abrasion at high temperature due to phenolic resin decomposition accompanying with abrasive wear and fatigue abrasion, the wear mechanism of friction materials of melamine modified phenolic resin brake pad is fatigue abrasion.
\end{abstract}

Keywords: Thermo-Mechanical Coupling, Carbon Fiber, Melamine Modified Phenolic Resin, Friction and Wear Performance

\section{Introduction}

In order to prolong the service life of brake lining, scientists are to reduce the wear of friction materials by improving the properties of material for along time [1-3]. The components of brake lining include binder, reinforcement and fillers, and the influence of binder on thermal fading and heat chap of brake lining is the most significant [4-6]. The poor ablation resistance of phenolic resin will affect the overall performance of friction material. High performance resin should have the following characteristics: excellent heat-resistance property, its hardness is low after resin is solidified, friction coefficient of friction material is stable, and braking noise is small [7-8]. Effective combination of melamine modified phenolic resin and carbon fiber can improve thermal fading and impact strength of brake lining.

\section{Finite Element Simulation Analysis of the Friction Process of Automobile Brake Pads}

\subsection{Establishment of Geometric Model}

Due to the friction of brake disc and brake pad, a large amount of heat is generated during the braking process of automobile which can influence the material performance and the braking performance of the brake pad [9-11]. Therefore, the analysis of thermal stress of brake pad during the braking process provides a theoretical basis for improvement of brake pad and accident prevention. Establish the finite element model of the brake disc and brake pad, as shown in Figure 1. Table 1 shows geometric dimensions of the brake disc and brake pad. 


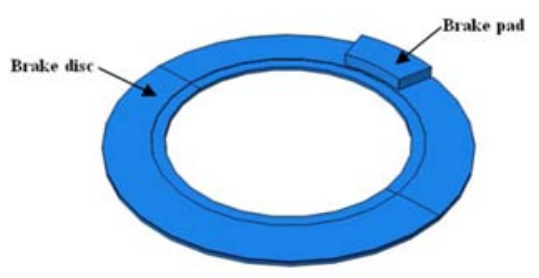

Figure 1. Finite element model of the brake disc and brake pad.

Table 1. Geometric dimensions of the brake disc and brake pad.

\begin{tabular}{llll}
\hline brake pair & $\begin{array}{l}\text { internal diameter } \\
\mathbf{d} \mathbf{1} / \mathbf{m m}\end{array}$ & $\begin{array}{l}\text { external diameter } \\
\mathbf{d} \mathbf{2} \mathbf{m m}\end{array}$ & $\begin{array}{l}\text { Thickness } \\
\mathbf{h} / \mathbf{m m}\end{array}$ \\
\hline brake disc & 135 & 90 & 20 \\
brake pad & 133 & 102 & 10 \\
\hline
\end{tabular}

\subsection{The Definition of Working Condition of Vehicle}

Automobile braking conditions for the initial braking speed $80 \mathrm{Km} / \mathrm{h}$, brake pressure $4 \mathrm{Mpa}$, total braking time $3 \mathrm{~s}$. The transient temperature field and stress field of brake pad under emergency braking conditions are analyzed. Consider the contact friction between the brake disc and the brake pad, and the two analysis steps are required: the first analysis step, put pressure on the brake pad, so that it to establish a stable contact relationship, second analysis steps to make the brake pad rotate 45 degrees.

\section{Experiment}

\subsection{Thermal Stress Analysis of Friction Materials}

From figure 2 and figure 3, we can see that the maximum temperature of the friction material of phenolic resin and melamine modified resin is 327.9 and 308 respectively in braking process. this is due to a heat recession of component of friction material caused by high temperature, resulting in the formation of abrasive grains, which is increased worn of friction material. So the serious wear region is corresponding to high temperature region. But the heat recession resistance of melamine modified phenolic resin friction material is better than that of phenolic resin. Therefore, during braking process the maximum temperature of melamine modified phenolic resin friction material is lower than that of phenolic resin, and the wear rate is lower. It can be seen from two figures that the high temperature region of friction material is mainly concentrated at the enter location of friction region. with the transfer of high temperature zone, wear will gradually transfer.
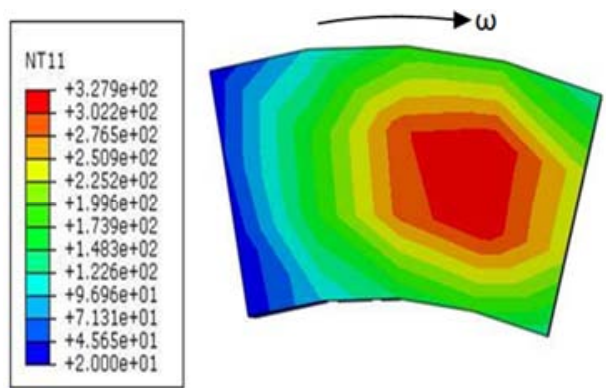

Figure 2. Temperature field distribution of phenolic resin friction material.

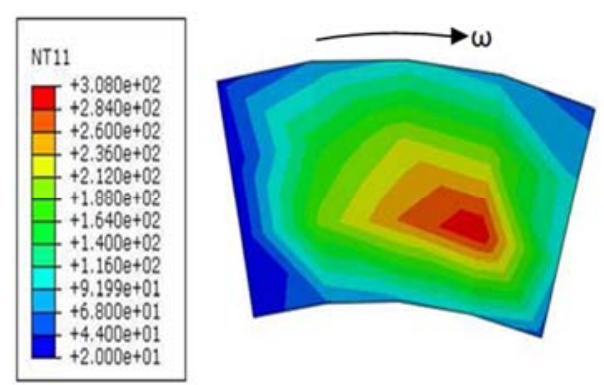

Figure 3. Temperature field distribution of melamine modified phenolic resin friction material.

From figure 4 and figure 5, the maximum stress value of phenolic resin friction material is $28.85 \mathrm{MPa}$, and the maximum stress value of melamine modified phenolic resin friction material is $20.55 \mathrm{MPa}$. the distribution of stress field of friction material is not uniform, and the position of highest temperature region is near the maximum stress region of friction material. In this region, the friction material is subjected to high temperature and contact pressure, which is easy to occur abrasive wear and fatigue wear. Therefore, under the influence of temperature field, the greater contact pressure, the more serious wear of the friction material.

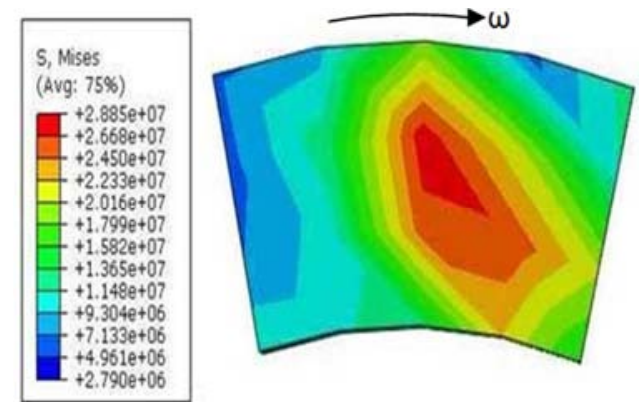

Figure 4. Stress field distribution of phenolic resin friction material.

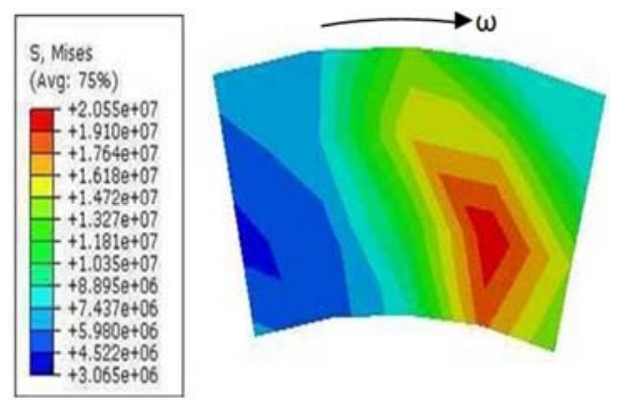

Figure 5. Stress field distribution of melamine modified phenolic resin friction material.

From the above analysis can be known, the wear area of friction material will be greatly affected under combined action of temperature field and stress field, the greater temperature and contact stress, the more serious wear of the area. The results of finite element analysis of two kinds of friction materials can be known. the highest temperature and maximum stress of melamine modified phenolic resin friction material is lower than that of phenolic resin, and friction coefficient is stable, and wear rate is low. 


\subsection{Main Component and Preparation}

The main raw materials are melamine modified resin, carbon fiber, wollastonite, barium sulfate, calcium sulfate, friction powder and graphite, and carbon fiber was produced by Shandong Fu Ying Biotechnology Co. Ltd., melamine modified resin was produced by Hangzhou Zhuo Li Chemical Co., Ltd., other materials were provided by Shandong Haili industrial group Huahong automobile brake parts Co. Ltd. And the test compound is shown in Table 2.

Table 2. Test compound (\%).

\begin{tabular}{|c|c|c|c|c|c|c|c|}
\hline melamine modified resin & carbon fiber & wollastonite & Barium sulfate & Calcium sulfate & friction powder & graphite & others \\
\hline 8 & 9 & 6 & 23 & 15 & 4 & 8 & 31 \\
\hline
\end{tabular}

\subsection{Preparation and Testing of Samples}

Uniform stirring of a certain proportion of raw materials in high-speed mixer for $10 \mathrm{~min}$. Then, after pressing and forming on cold stamping die, the billet are put into hot embossing mould (hot pressing temperature is $150^{\circ} \mathrm{C}$ pressure is $120 \mathrm{MPa}$, hot pressing time is $20 \mathrm{~min}$ ). Cooling to room temperature after hot press molding, and 4-hour thermal treatments at $150^{\circ} \mathrm{C}$.

Mechanical properties of samples were measured by XJJ-5 charpy impact testing machine and XHRD-150 plastic rockwell hardness testing machine. Determination of friction and wear properties of samples with XD-MSM constant speed friction tester. FEI QUANTA FEG250 scanning electron microscopy was used to observe surface morphology and wear morphology of friction material. Component of samples by INCAE Energy X-MAX-50 X - ray spectrometer.

\section{Results and Discussions}

\subsection{Mechanical Properties of Friction Materials}

Table 3 shows the mechanical properties results of friction materials. The sample 1 present friction material with melamine modified phenolic resin, Sample 2 presents phenolic resin friction material. From the table shows that the resin used in friction material is different, the mechanical properties will be changed. toughness of phenolic resin was improved by melamine, and bond strength between carbon fiber and matrix was enhanced by the modified resin[12], so the impact toughness and fracture toughness of melamine modified phenolic resin friction material are larger than that of phenolic resin. Due to bonding strength of filler for friction material were enhanced by melamine modified phenolic resin, so hardness of sample 1 is greater than sample 2, but the hardness of two samples is within specified range. As we can see from the result, the melamine modified phenolic resin can improve mechanical properties of friction material.

Table 3. Mechanical properties of friction material.

\begin{tabular}{lll}
\hline Sample & $\mathbf{1}$ & $\mathbf{2}$ \\
\hline Hardness $(\mathrm{HRL})$ & 65 & 62 \\
Impact toughness $\left(\mathrm{KJ} / \mathrm{cm}^{2}\right)$ & 5.1 & 4.4 \\
Fracture toughness $\left(\mathrm{MPa} \cdot \mathrm{m}^{1 / 2}\right)$ & 4.8 & 4.2 \\
\hline
\end{tabular}

\subsection{Friction and Wear Properties of Friction Materials}

Table 4 shows the friction and wear properties results of friction materials. Table shows test results of friction coefficient and wear rate of friction materials. In order to analyze the change of friction coefficient and wear rate with temperature, table 4 is made into figure 6 and figure 7 . From figure 6 can be known sample 1 has no obvious thermal fading and the stability of friction coefficient is better than that of sample 2 in the whole process of experiment. When the temperature is increased from 250 to 350 , the friction coefficient of sample 2 is decreased from 0.43 to 0.38 , and the phenomenon of thermal degradation is obvious. From figure 7 , At low temperature, the wear rate of two samples are similar. After $200^{\circ} \mathrm{C}$, the wear rate of sample 2 was significantly higher than that of sample1. The analysis results show that melamine modified phenolic resin has excellent high temperature bonding effect.

Table 4. Friction and wear properties of friction materials.

\begin{tabular}{lllll}
\hline \multirow{2}{*}{ Temperature $\left({ }^{\circ} \mathbf{C}\right)$} & \multicolumn{3}{l}{ Friction coefficient $(\boldsymbol{\mu})$} & \multicolumn{2}{l}{ Wear rate $\left(\mathbf{1 0}^{-\mathbf{7}} \mathbf{c m} / \mathbf{N} . \mathbf{m}\right)$} \\
\cline { 2 - 5 } & $\mathbf{1}$ & $\mathbf{2}$ & $\mathbf{1}$ & $\mathbf{2}$ \\
\hline 100 & 0.32 & 0.33 & 0.07 & 0.12 \\
150 & 0.36 & 0.37 & 0.08 & 0.15 \\
200 & 0.41 & 0.4 & 0.07 & 0.16 \\
250 & 0.4 & 0.41 & 0.1 & 0.2 \\
300 & 0.38 & 0.44 & 0.13 & 0.22 \\
350 & 0.37 & 0.43 & 0.1 & 0.3 \\
\hline
\end{tabular}

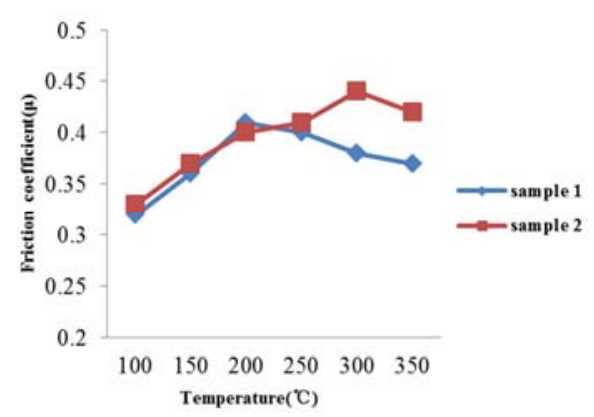

Figure 6. The changes of friction coefficient of friction materials with temperature.

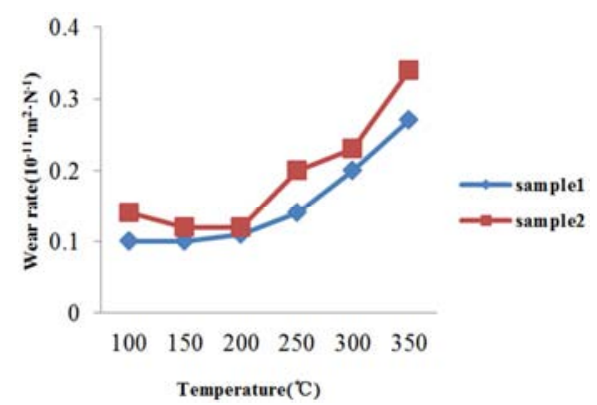

Figure 7. The changes of wear rate of friction materials with temperature. 


\subsection{Analysis of Fracture Surface Morphology of Friction Materials}

From figure 8(a), we can find that tight bonding between carbon fiber and matrix of sample 1 friction material. it shows that melamine modified phenolic resin has good bonding effect, so that the friction material is kept high bonding strength in friction process, the friction coefficient is stable, and the wear rate is small. From figure 8(b) shows that combination strength of carbon fiber and matrix of sample 2 friction material is not enough, and carbon fiber is easy to be pulled out from the base by friction force, which makes friction coefficient of friction material is not stable, the wear rate is large, and the wear is serious.

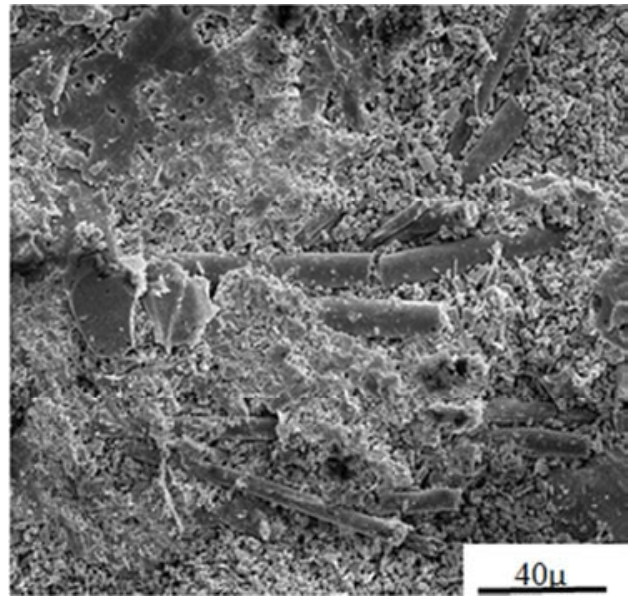

(a) SEM image of fracture surface of sample 1.

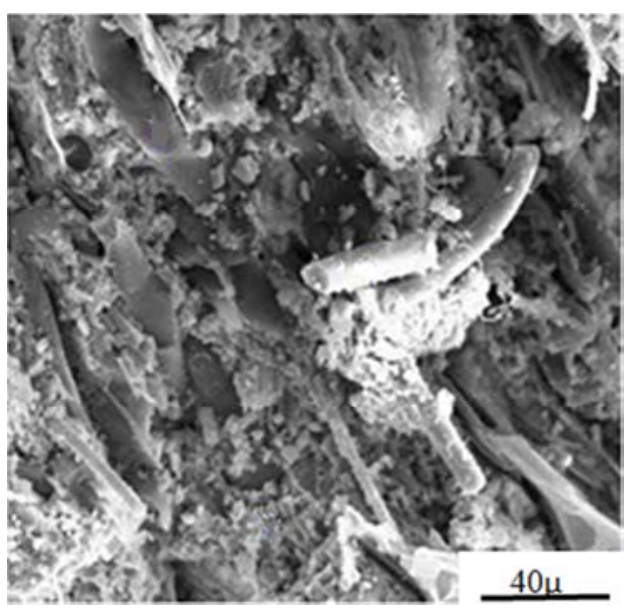

(b) SEM image of fracture surface of sample 2.

Figure 8. SEM image of fracture surface of friction materials.

From figure 9(a), we can find that the wear surface of sample 1 is smooth and flat, with a slight scratches and a small amount of chipping pit. Melamine modified phenolic resin has a favourable high adhesion and the thermal decomposition is not easy to occur at high temperature. The components of friction material can be stably bonded together, so that the friction coefficient of sample 1 is stable, and the wear amount is relatively small. But friction material will be the role of cyclic stress in friction process [13-15], it causes fatigue fracture of material on friction surface and fall off to form spalling pits. The friction form of sample 1 is mainly fatigue wear. From Figure 9(b), we can find that wear surface of sample 2 has pits formed by spalling of materials. it is due to thermal decomposition of phenolic resin at high temperature so that the stability of friction layer is reduced, which resulting in friction layer rupture and fall off to form pits. And shedding material also will scratch surface of friction. In addition, the thermal decomposition of phenolic resin also causes fiber to be pulled out from the base, so that friction surface is formed into pits. The friction form of sample 2 is mainly abrasive wear and fatigue wear.

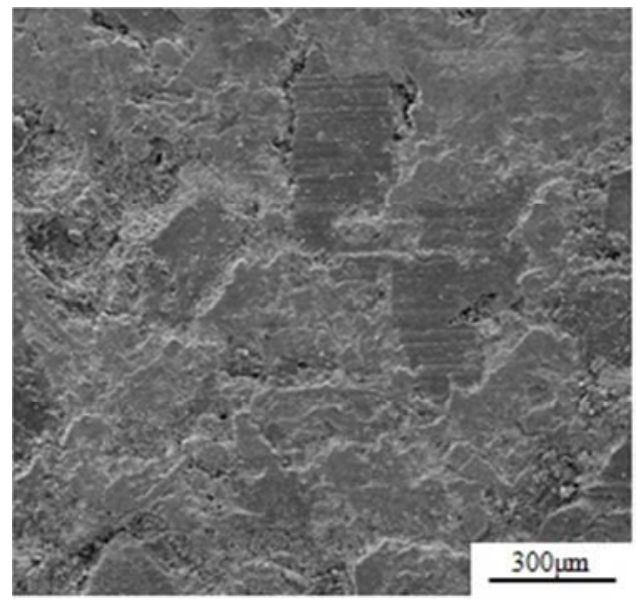

(a) SEM images of worn surfaces of sample 1.

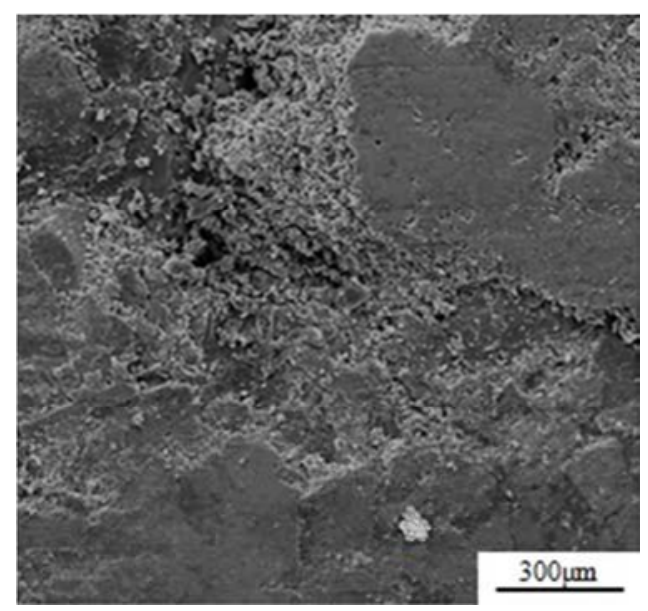

(b) SEM images of worn surfaces of sample2.

Figure 9. SEM images of worn surfaces of friction materials.

\section{Conclusion}

(a) From the analysis of tridimensional finite element, it is known that the temperature field and stress field distribution of brake pads are not uniform, and the position of the highest temperature region and the maximum stress region appear at entrance of friction surface. brake pad has occurred biased friction under combined action of temperature field and stress field, and the most wear region is mainly concentrated in the 
highest temperature region and the maximum stress region of brake pad.

(b) The hardness, impact toughness and fracture toughness of melamine modified phenolic resin were improved by comparing with phenolic resin, and its mechanical properties are in range of national standard.

(c) Compared with phenolic resin friction materials, the friction coefficient of melamine modified phenolic resin is stable, and its wear rate is relatively small. The thermal fading of melamine modified phenolic resin is not significant at high temperature, so that friction and wear properties of friction materials are stable.

(d) Compared with phenolic resin friction materials, the abrasive wear of melamine modified phenolic resin was decreased, and its wear surface was relatively smooth. The main wear form of melamine modified phenolic resin friction material is fatigue wear, the wear form of phenolic resin friction material is mainly abrasive wear and fatigue wear.

\section{Acknowledgements}

This work was supported by the National Natural Science Foundation of China (Grant No. 51575234), Shandong province Natural Science Foundation (Grant No. ZR2015JL018, ZR2014EL026), Key R\&D Program of Shandong province (Grant No. 2015GNC112009).

\section{References}

[1] L Xiaobin, L Chengshun, L Ping, J Guihua. "Research situation and development about the non-asbestos friction material of automotive brake pad," J. Materials Review, 2013, 27, pp. $265-267$.

[2] $\mathrm{P}$ jianmin, $\mathrm{X}$ Jingli, $\mathrm{Y}$ chengbing. "Research progress in NAO brake pad resin matrix," J. Materials Review, 2007, 21, pp. 371-376.

[3] K Haijuan, Z Rui, Z Jianjun, M Yu, T Cuiqing, Y Muhuo. "The research status and progress of aramid fiber," J. MATERIALS CHINA, 2013, 32 (11), pp. 676-684.
[4] Z Xinyuan, H Bixia, L Jianli, Z Yuan. "Property and application of high-performance carbon fiber," J. Cotion Textile Technology, 2011, 39 (4), pp. 269-272.

[5] Z Xiaohu, M Yu, Z Wei. "The state of the art and trend of carbon fiber reinforced composites," J. FIBER COMPOSITES, 2004, 1 (50), pp. 50-53.

[6] X Xin, C Guangxu, L Feiqing, Z Wanchun. "Research progress of friction properties for fiber reinforced resin matrix composites," J. Journal of Materials Science \&Engineering, 2005, 23 (3), pp. 457-461.

[7] Z Feng, L Hu, L Changyu. "Synthesis of high-temperatureresistance of phenolic for friction material," J. Guangzhou Chemical Industry, 2011, 39 (2), pp. 83-84.

[8] L Yang, X Tao, L Ruibo, H Ting, Y Wenyong. "Preparation and applicasion of modified phenolic resin used for friction materials," J. Plastics Science and Technology 2013, 41 (10), pp. 63-67.

[9] C Lin, Z Wenming. "Research on coupling field of disk brake based on finite element" J. Tractor \& Farm Transporter, 2009, 36 (5), pp. 43-45.

[10] C Hongsheng. "A finite element analysis on thermal-solid coupling analysis of friction plate" J. FOOD\&MACHINERY, 2011, 27 (1), pp. 81-83.

[11] R Bing, C Kainian. "Analysis of the thermal-structure coupling on the friction plate of the disc brake" J. Machinery Design \& Manufacture, 2011, 27 (1), pp. 81-83.

[12] Y Fei, L Ying, D Guo, B Yongqiang. "Friction and wear properties of carbon fiber reinforced resin-based friction material,” J. Aerospace Materials \& Technology, 2016, 2, pp. 31-35.

[13] H Peng, Q Lu. "Modification and application of melamine," J. CHINA PLASTICS INDUSTRY, 2006, 34, pp.136-138.

[14] Y Guanxin, W Yuling, W Qinglong, N Huawei. "Effects of modification of $\mathrm{PF}$ resin on the performances of brake friction materials," J. LUBRCATION ENGINEERING, 2015, 40 (8), pp. $22-25$.

[15] L Yuan, D Jie, L Jun, Z Xuemei, F Xiaoqin. "Preparation and characterization of brake friction compound modified phenolic resin," J. Science and technology project, 2015, pp. 61-63. 